\title{
Undergraduate pre-service chemistry teachers' conceptions about inorganic qualitative analysis
}

\author{
Hanson ${ }^{21}$, R.
}

\begin{abstract}
The research was a baseline study to determine the perceptions and alternative concepts that pre-service teachers' have which hinder them from making correct inferences during practical inorganic chemistry experiments. A two-tier qualitative analysis diagnostic instrument (QADI) was developed and used to diagnose and treat the participants' alternative concepts in inorganic chemistry qualitative analysis. The diagnostic instrument was administered to 78 pre-service teachers in the University of Education, Winneba, Ghana. The study revealed that students' inabilities to make correct inferences or write and balance equations for suspected reactions correctly were the main hindrances to successful qualitative analytical activities. They often resorted to guess work. The most prevalent conceptions were their inability to predict and distinguish between chalky and gel precipitates especially when aqueous ammonia and sodium hydroxide were used on test samples. They were also unable to distinguish insoluble salts from true precipitates. A post administration of the QADI after the treatment period showed that the intervention worked positively to increase pre-service teachers' content knowledge in inorganic chemistry and their understanding of inorganic qualitative analytical work.
\end{abstract}

Keywords alternative concepts, content knowledge, inorganic chemistry, pre-service teachers, qualitative analysis

\section{Introduction}

Qualitative analysis is a branch of chemistry that deals with the identification of elements or grouping of elements present in a sample. The techniques employed in qualitative analysis vary in complexity, depending on the nature of the sample. In some cases it is necessary only to verify the presence of certain elements or groups for which specific tests applicable directly to the sample (e.g., flame tests, spot tests) may be available. More often the sample is a complex mixture, and a systematic analysis must be made in order that all the constituents may be identified. It is customary to classify the methods into two classes: qualitative inorganic analysis and qualitative organic analysis.

The classical procedure for the complete systematic analysis of an inorganic sample consists of several parts. First, a preliminary dry test may be performed, which may consist of heating the sample to detect the presence of such constituents as carbon (marked by the appearance of smoke or char) or water (marked by the appearance of moisture) or introducing the sanmple into a flame and noting the colour produced. Certain elements may be identified by means of their characteristic flame colours. After preliminary tests have been performed, the sample is commonly dissolved in water for later determination of anionic constituents (i.e., negatively

\footnotetext{
${ }^{21}$ Ruby Hanson lectures at the Department of Chemistry Education, University of Education, Winneba, Ghana
} 
charged elements or groupings of elements) and cationic constituents (i.e., positively charged elements or groupings of elements). The procedure followed is based on the principle of treating the solution with a succession of reagents so that each reagent separates a group of constituents. The groups are then treated successively with reagents that divide a large group into subgroups or separate the constituents singly. Portions of the material are dissolved separately, and different procedures are used for each to detect the cationic and anionic constituents. A typical analytical scheme for the separation of the cations into groups is summarized in the table. The analysis for anions is more difficult and less systematic than that for cations.

Qualitative analysis is used to separate and detect cations and anions in a sample substance. In an educational setting, it is generally true that the concentrations of the ions to be identified are all approximately $0.01 \mathrm{M}$ in an aqueous solution. The 'semimicro' level of qualitative analysis employs methods used to detect 1-2 $\mathrm{mg}$ of an ion in $5 \mathrm{~mL}$ of solution.

First, ions are removed in groups from the initial aqueous solution. After each group has been separated, then testing is conducted for the individual ions in each group. Many reagents are used in qualitative analysis, but only a few are involved in nearly every group procedure. The four most commonly used reagents are $0.1-6 \mathrm{M} \mathrm{HCl}, \mathrm{HNO}_{3}, \mathrm{NaOH}$, and $\mathrm{NH}_{3}$. Understanding the uses of the reagents is helpful when planning or carrying out an analysis.

In order to make good inferences in QA one must have excellent background knowledge of the reactions that occur between the common bench reagents and test ions which could most likely be assigned them in analytical work. Lenton and Turner (1999) found that science graduates did not necessarily understand or have sound knowledge of all parts of their own specialized subject; and that teaching or training in the subject area during a teacher training course did not always improve subject matter knowledge. 'Teachers' knowledge about the subject matter and their conceptions about the phenomena they teach can enhance or limit students' learning', (Valanides, 2000, p.250). Lenton and Turner (1999) were concerned that preservice teachers could perpetuate the teaching of basic misconceptions in science. Studies have shown that preservice teachers have alternative concepts (ACs) similar to those of students and so could unwittingly transmit these ACs to their students, thereby setting up a vicious cycle of ACs among students (Quilez-Pardo \& Solaz-Portoles, 1995; Lin, Cheng \& Lawrenz, 2000). It is therefore important that pre-service teachers' ACs are identified and corrected so that they do not transfer them to their own students later on in their careers.

A qualitative analysis experiment is a part of the West African Secondary School Certificate Examination (WASSCE) practical test for all elective chemistry senior high school students in Ghana. In this qualitative analysis (QA) students carry out series of procedures using chemicals often termed as reagents on given test samples which are unknown so that their cationic or anionic composition is determined. Here, students have to observe carefully for changes in constitution, colour and evolution of gases which sometimes occur. Upon these observed basic changes certain inferences are made which lead to a deduction of the ions contained in the test sample. In order to make sense of the procedures, reactions and results in QA practical work, knowledge of topics such as acids and bases, salts, periodicity, reactivity of metals, balancing of chemical equations are important pre-requisites. Without such 
knowledge of required theory to guide their experiments they would not know what to take note of in the experiments (Hart, Mulhall, Berry, Loughran \& Gunstone, 2000)

A number of studies have found QA to be a difficult topic for secondary students, (Duit \& Treagust, 1995; Gunstone, 1994; Wittrock, 1994; Nakhleh \& Krajcik, 1994; Herron, 1996, Tan, Goh, Chia \& Treagust, 2001, 2002,) They asserted that the difficulties were due to reasons such as the content of the topic, lack of appropriate framework, the lack of cognitive strategies, cognitive overloading and the lack of mastery of process skills. Another possible reason was attributed to their teachers not having adequate understanding of the reactions and procedures involved and so are therefore unable to teach for understanding. Students do not encounter QA in normal everyday life except in the laboratory. Thus its principles and theories will not come to them easily except by constant practice. The concepts behind the procedures in QA and the reactions that occur are abstract, complex and extensively linked to other concepts. It involves a mix of knowledge and skills such as propositional and procedural knowledge, manipulative and inferential skills (Tan, 2005). This makes the whole process demanding and difficult.

Information available on this topic in the annual West African Secondary School Certificate Examination (WASSCE) chief examiners' report on each year's performance in chemistry was not encouraging.. The report for the last decade reiterated that candidates' main weakness was their inattention to the nature and proper colour of precipitates and solutions. There was no logical relation in the kind of test they performed, their observations and inferences (WAEC, 2002). Teachers were advised to demonstrate proper procedures for qualitative analysis (QA) to their students.

During the treatment period, (after diagnosis) Micro Chemistry Equipment (MCE) was employed as the main lab ware due to its numerous benefits and inherent constructivists model for teaching and learning. The micro Chemistry Equipment (MCE) is a small-sized kit containing simple plastic equipment for the conduct of school science activities even outside the conventional laboratory, such as the classroom, home or under a tree. The specific contents are a comboplate which has small and large sized well which serve as test tubes or beakers according to the needs of the activity. Its other contents are a syringe, propettes, a light emitting diode for confirmation of current flow, a micorburette for acid-base titrations, indicator papers, micro spatulas and plasticine.. Standard practical activities have been designed for use with this kit from the Centre for Research and Development in Mathematics, Science and Technology Education (RADMASTE), South Africa.

The MCE is an alternative approach to overcome some problems associated with practical work as it provides hands-on activities and personal experiences for students by using reduced amounts of chemicals, and miniature lab ware. It is safe, and easy to manipulative. Precision and accuracy of experiments is not compromised. It is even enhanced in this case. It improves students' skills in handling equipment. It fosters an attitude of carefulness and patience. Kelkar and Dhavale (2000) reported that undergraduate students performed experiments with more care and showed enhanced skills in handling standard conventional equipment after adopting the use of MCE. This affirms the high accuracy that users of the MCE gain.

\section{Context of the study}

The study sought to investigate undergraduate teacher-trainees' understanding, alternative concepts (ACs) and situational knowledge related to inorganic chemistry qualitative analysis as measured by the Qualitative Analysis Diagnostic Instrument (QADI) which was adapted from 
an earlier study. The MCE was employed as an intervention in inorganic chemistry qualitative analysis practical lessons during the treatment period. This study was necessary to conduct so as to be able to unearth misconceptions of pre-service teachers and to correct them with sound scientific reasons before they went out to teach. Based upon literature available on issues of students' performance and the context of the study, the following research questions were formulated to guide the study

I) What kind of alternative concepts in inorganic chemistry qualitative analysis are common among pre-service teachers at the University of Education, Winneba?

II) Would the use of the QADI be an effective tool in diagnosing pre-service teachers' alternative concepts?

III) How would the use of Micro chemistry Equipment (MCE) in performing chemistry practical activities improve pre-service teachers' conceptions in inorganic qualitative analysis class?

\section{Methodology}

In this research, Ghanaian pre-service teachers' conceptual understanding of the underlying reactions in QA was examined and evaluated. A two tier multiple choice diagnostic instrument used by Tan (2001) was adapted for use. The first tier choices examined factual knowledge while the second tier examined the reasons behind the first tier. Validity of the instrument was censured by clearly specifying the concepts to be tested and giving them to senior faculty members to analyze for validity. The items were developed based on known student misconceptions, responses from classroom discourse and constructed-response items. Such data have been used to develop diagnostic tests on diffusion and osmosis (Odom \& Barrow, 1995), chemical bonding (Tan \& Treagust, 1999), chemical equilibrium (Tyson, Treagust \& Bucat, 1999) as well as qualitative analysis (Tan, 2000).

The two-tier QADI was developed using the 3-phase procedure defined by Treagust (1995). The first phase involved a definition and validation of the framework of the Senior High School chemistry syllabus and qualitative analysis required for the West African Secondary School Certificate Examination (WASSCE). The syllabus comprises both inorganic and organic analytical sections but only the inorganic section was considered in this research as students involved were offering it for their practical work in the semester. Besides it had been observed to be more problematic for students than the organic analytical work (WAEC, 2004).

The second phase involved the identification of secondary students' alternative conceptions of qualitative inorganic analysis from the WASSCE chief examiner's reports $(2002,2004)$ which discuss students' performance in both the practical work and free-response written tests. This was necessary as the Senior High School (SHS) was the target practicing school for the teacher trainees. In the third phase, the data collected was used as a basis for construction of the instrument used. This was refined through field trials. The validity was established by five seasoned secondary chemistry teachers and three tertiary senior lecturers.

After identification of the pre-service teachers' alternative conceptions, the Micro Chemistry Equipment (MCE) was employed as an intervention in all qualitative practical exercises to facilitate the pre-service teachers' understanding of the concepts behind inorganic qualitative analysis.

The QADI was administered to 78 first year pre-service chemistry teachers at the University of Education (UEW), who had all passed chemistry at the SHS level and were training to teach in 
the SHS as well as Junior High Schools (JHS) on completion of their training programme Students were given the QADI to answer at the beginning of their chemistry practical course. These were marked and the results analyzed. The same test was administered at the end of the course after MCE activities were employed as a form of intervention. SPSS was used in the analysis of obtained results.

\section{Results and discussion}

Table 1 shows the performance of pre-service teachers on the QADI before and after the treatment period. There was a significant difference between the two scores obtained $(\mathrm{p}<0.000)$.

Table 1 Paired Pre \& Post sample statistics for QADI

\begin{tabular}{lllll}
\hline & Mean & N & T & Sig (2-tailed) \\
\hline Pre-test & 8.78 & 78 & & \\
Post-test & 12.72 & 78 & & \\
Pair 1 \& 2 pre-test-post-test & 3.94 & 78 & 12.66 & 0.000 \\
\hline
\end{tabular}

The means were 8.78 and 12.72 respectively for the QADI pre- and post-tests. The substantial increase in the post test mean score was a reflection of improvement in the students' answers for the activities they performed after the intervention. The paired sample t-test analysis yielded a T-value of 12.66 and a p-value of 0.000 , an indication that the difference between students' pre- and post-test mean scores was statistically significant.

Individual analysis of post-test papers indicated that students still had a few alternative conceptions which required further work. This assertion was made if particular question items had less than $40 \%$ score on the average. Students were not conversant with scientifically accepted concepts in these cases. Very erratic answers were supplied by students to such question items which was an indication of guess work and not so much a misconception which had been imbibed by students. Highly scored items were incidentally correct options. This was an indication of their understanding of at least certain concepts. It was again an index of their understanding of the questions being asked in the QADI. It could be deduced also that the QADI executed the purpose for which it was intended in diagnosing students' learning difficulties in qualitative analysis.

The alternative concepts (ACs) were grouped under the headings of inability to answer explanatory questions and inability to identify precipitates with the correct descriptive terms. If $50 \%$ of the group failed to answer a question correctly the concept being tested was considered an alternative concept and had to be addressed. At the end of the research, a few ACs were still found to be prevalent and will need to be dealt with in subsequent studies. The most evident Ac held by students was identification and the description of precipitates formed (that is the colour and nature of precipitates). Some ions have characteristic colours in solution. These were not adequately mastered by students. Their chemistry was little known to students also. For example, all transition ions, apart from $\mathrm{Zn}^{2+}$ and $\mathrm{Sc}^{+}$have characteristic colours which are used as clues in qualitative analysis to identify them, as in the case of iron and copper ions which are commonly dealt with at senior high school level. Other ACs were pre-service teachers' lack of relevant skills for adequate qualitative analysis.. If a given salt was insoluble 
in water, they described the observed insolubility as 'a precipitate'. They could not comprehend that salts do not form precipitates in water. They are either described as being 'soluble' or 'insoluble' in water. One test for chloride ions is to add aqueous silver nitrate (V) to the unknown solution. If chloride is present, the silver chloride precipitate will be formed and will react with excess aqueous ammonia to form a soluble silver ammine. Many preservice teachers did not know or apply this chemical concept and so could not correctly explain the chemistry behind their observation when they had this in one of their test items. Their confirmatory tests for suspected ions were incomprehensible and illogical. Suspected gases were inadequately described. No chemical tests were carried out too confirm their suspicions. Students were not able to relate what they had learned in class to what they did in practical work. Teachers therefore need to make these links explicit to students as often and correctly as possible so that students will be able to acknowledge the links.

It could be observed from the sample alternative answers given in Table 2 that students could not even put together ions that they had (wrongly) suspected to form a suspected given salt for analysis. The pre-service teachers could not draw relationships between similar or different outcomes. They could for example not relate the use of silver ions on halides as a test for halides and perhaps even a confirmatory test, if a halide had been inferred earlier on in their work. They could not distinguish between common reagents used for cations and those for anions. This was a clear indication that students carried out these activities mechanically; simply following instructions and not making any scientific deductions from their personal observations. This suggests that a closer look should be given to how teachers teach qualitative analysis and the theory behind it. The 2006 chief examiners' report for West African Senior Secondary Certificate Examination (WASSCE) reveals that most candidates were ignorant of reasons for the basic laboratory procedure (West African Examinations Council, 2006. p.69). The report added that candidates were unable to make meaningful inferences from correct observations.

In all the practical activities, the MCE was used so that students could perform the assigned activities in relatively shorter periods as compared to using the larger orthodox glass ware. The shorter work period and minimum amount of chemicals used implied that the activities could be performed several times over until students were convinced about certain concepts at relatively lower cost.

The pre-service teachers did not show much consistency in their ACs. According to Tan (2000), Palmer (1999, p. 639) proposes that 'his personal propositions' model (p. 649) provides an explanation for students' inconsistencies in science and the prevalence of these even through tertiary level . Taber (1999) also used a diagnostic instrument on ionization energy and found that 'apparently related items do not always receive a constant level of support from the students. Like Palmer, he thinks that students have many alternative explanations which are applied based on a particular context in which it is found. A study by Voska and Heikkinen (2000) on student conceptions in chemical equilibrium also indicated that only a small number of studies showed consistency in their thinking. 


\begin{tabular}{|c|c|c|c|}
\hline Question/item/Activity & Alternative concept/observation & $\begin{array}{l}\text { Correct } \\
\text { concept/observation }\end{array}$ & Chemical concept \\
\hline $\begin{array}{l}\text { 1(a). Dispense } 5 \text { drops of the following } \\
\text { solutions: sulphuric acid }(1.0 \mathrm{M}) \text { into well } \\
\mathrm{A}[2] \text { ' calcium carbonate }(0.5 \mathrm{M}) \text { into well } \\
\mathrm{A}[3] \text { and zinc nitrate }(0.5 \mathrm{M}) \text { into well } \\
\mathrm{A}[4] \text {. Use a clean propettes for each } \\
\text { solution. Then dispense one drop of } \\
\text { barium chloride into each of the wells } \\
\text { A[1] to A[4]. Record observation }\end{array}$ & $\begin{array}{l}\text { - } \mathrm{No} \text { observation } \\
\text { - } \mathrm{No} \text { reaction } \\
\text { - } \mathrm{CO}_{2} \text { gas evolved } \\
\text { - } \mathrm{Reaction} \\
\text { - } \mathrm{Gas} \text { evolved } \\
\text { - } \mathrm{CaCl} \\
\text { - } \mathrm{Ba}_{2} \mathrm{SO}_{4} \\
\text { - } \mathrm{ZnCl}_{2} \mathrm{Cl} \\
\text { - } \mathrm{ZnSO}_{4}\end{array}$ & $\begin{array}{l}\text { Wells } A[1] \& A[4] \text { remain } \\
\text { clear } \\
\text { Wells } A[2] \& A[3] \text { turn } \\
\text { cloudy }\end{array}$ & $\begin{array}{l}\text { The formed products calcium chloride } \\
\text { and zinc chloride are both soluble in } \\
\text { water and so no precipitate will be } \\
\text { observed in wells } 1 \& 4 \\
\mathrm{BaSO}_{4(\mathrm{~S})} \text { and } \mathrm{BaCO}_{3(\mathrm{~s})} \text { will be formed } \\
\text { in well } 2 \text { \& } 3\end{array}$ \\
\hline $\begin{array}{l}\text { 1(b). Write a chemical formula to represent } \\
\text { any precipitates observed }\end{array}$ & - $\mathrm{H}_{2} \mathrm{SO}_{4}+\mathrm{BaCl}=\mathrm{BaSO}_{4}+\mathrm{HCl}$ & & \\
\hline $\begin{array}{l}\text { 2. (Part of a different practical test) } \\
\text { From your observation, is it possible to } \\
\text { distinguish which halide was present in } \\
\text { solution by adding silver nitrate? Explain } \\
\text { your answer }\end{array}$ & $\begin{array}{l}\text { Some students answered 'No' and } \\
\text { explained that all halides have the same } \\
\text { colour or characteristic identification; they } \\
\text { formed precipitates }\end{array}$ & $\begin{array}{l}\text { Yes } \\
\text { The precipitate that formed } \\
\text { in each well had a different } \\
\text { colour. Silver chloride is } \\
\text { white; Silver bromide is } \\
\text { yellow and Silver iodide is } \\
\text { deep yellow }\end{array}$ & $\begin{array}{l}\text { The halide ions have different } \\
\text { characteristic colours based on } \\
\text { characteristics such as size and } \\
\text { position on the periodic table }\end{array}$ \\
\hline $\begin{array}{l}\text { 3a. To a portion of filtrate add sodium } \\
\text { hydroxide solution in drops and then in } \\
\text { excess }\end{array}$ & $\begin{array}{ll}- & \mathrm{Cl}^{-} \\
- & \mathrm{Ca}^{2+} \\
\text { - } & \mathrm{NH} 4 \\
\text { - } & \mathrm{NH}_{4}^{+} \\
\text {- } & \mathrm{CO}_{3}^{2-}\end{array}$ & $\begin{array}{l}\text { A white gelatinous } \\
\text { precipitate will be observed } \\
\text { which dissolves in excess. } \\
\text { Inference to be made would } \\
\text { be } \mathrm{Zn}^{2+} \text { or } \mathrm{Al}^{3+}\end{array}$ & $\begin{array}{l}\text { The test reagents } \mathrm{NaOH}(\mathrm{aq}) \text { and } \\
\mathrm{NH}_{3(\mathrm{aq}) \text { all react with the zinc and }} \\
\text { aluminium cations but ammonia is a } \\
\text { distinguishing reagent for the two as it } \\
\text { forms a precipitate even in excess with } \\
\mathrm{Al}^{3+} \text { ions but not with } \mathrm{Zn}^{2+} \text {. }\end{array}$ \\
\hline $\begin{array}{l}\text { 3b. To another portion of filtrate add } \\
\text { aqueous ammonia in drops and in excess }\end{array}$ & $\begin{array}{l}\text { - } \quad \text { Chalky precipitate } \\
\text { - } \quad \text { Clear solution (participant failed } \\
\text { - } \quad \text { add in drops first) } \\
\text { - } \quad \mathrm{Al}^{3+} \text { confirmed in part } 3 \mathrm{~b} .\end{array}$ & $\begin{array}{l}\text { A white gelatinous } \\
\text { precipitate would be } \\
\text { observed and } \mathrm{Zn}^{2+} \text { confirmed }\end{array}$ & $\begin{array}{l}\text { The issue of amphoterism must be } \\
\text { understood in the reactions of these } \\
\text { ions also. A complex is formed in the } \\
\text { case of the latter test, which is } \\
\text { characteristic for a reaction between } \\
\text { ammonia and zinc. }\end{array}$ \\
\hline
\end{tabular}


Undergraduate pre-service chemistry teachers' conceptions about inorganic qualitative analysis Hanson, R.

Table 2 A compilation of some of the pre-service teachers' identified alternative concepts (continued)

\begin{tabular}{|c|c|c|c|}
\hline Question/item/Activity & Alternative concept/observation & $\begin{array}{l}\text { Correct } \\
\text { concept/observation }\end{array}$ & Chemical concept \\
\hline $\begin{array}{l}\text { 4a. To a portion of a resulting filtrate } \\
\text { (residue + dilute nitric acid) dilute NH3 is } \\
\text { added in drops and in excess } \\
\text { 4b. Is any precipitate formed? State the } \\
\text { colour if any and explain why it is not the } \\
\text { white colour that is often observed. }\end{array}$ & $\begin{array}{l}\text { Most participants correctly observed a pale } \\
\text { blue gel precipitate which dissolves in } \\
\text { excess reagent to form a deep blue } \\
\text { solution. Inference such as } \mathrm{Ca}^{2+,} \mathrm{Al}^{3+} \mathrm{Fe}^{3+} \\
\text { and even } \mathrm{Fe}^{2+} \text { were made. }\end{array}$ & $\begin{array}{l}\mathrm{Cu}^{2+} \text { present } \\
\text { A hint on colour was given } \\
\text { but participants missed it }\end{array}$ & $\begin{array}{l}\text { Copper ions in solution have a } \\
\text { characteristic blue colour. Copper is a } \\
\text { transition metal and has the capacity to } \\
\text { exhibit different shades of colour } \\
\text { based upon the ligand with which it is } \\
\text { complexing or bonding. }\end{array}$ \\
\hline $\begin{array}{l}\text { 5a. Sample + dil. } \mathrm{HCl} \\
\text { Test any gas which evolves with lead } \\
\text { acetate paper }\end{array}$ & $\begin{array}{l}\text { Effervescence observed with rotten egg } \\
\text { smell characteristic of } \mathrm{H}_{2} \mathrm{~S} \text { g). Yet students } \\
\text { inferred } \mathrm{CO}_{2}(\mathrm{~g}), \mathrm{N}_{2}(\mathrm{~g}), \mathrm{NO}_{2}(\mathrm{~g}) \text { and } \mathrm{SO}_{2} \\
(\mathrm{~g}) \text {. }\end{array}$ & $\begin{array}{l}\mathrm{H}_{2} \mathrm{~S} \text { gas evolved. } \\
\mathrm{S}^{2}\end{array}$ & $\begin{array}{l}\text { The gas turned the lead acetate paper } \\
\text { black due to the formation of lead } \\
\text { sulphide }\end{array}$ \\
\hline b. Filtrate from $5 \mathrm{a} .+\mathrm{NaOH}$ solution & $\begin{array}{l}\text { Various colours such as bluish-green, } \\
\text { brown and blue were observed by students } \\
\text { Precipitate dissolves }\end{array}$ & $\begin{array}{l}\text { Dirty-green precipitate } \\
\mathrm{Fe}^{2+} \text { present }\end{array}$ & $\begin{array}{l}\text { The characteristic colour of } \mathrm{Fe}^{2+} \text { ions } \\
\text { (a transition metal) is observed }\end{array}$ \\
\hline c. Filtrate $+\mathrm{NH}_{3}(\mathrm{aq})$ & $\begin{array}{l}\text { Solution changes to green } \\
\text { Precipitate changes } \\
\mathrm{Fe}^{3+} \text { present }\end{array}$ & $\begin{array}{l}\text { Dirty green precipitate } \\
\mathrm{Fe}^{2+} \text { present }\end{array}$ & $\begin{array}{l}\text { The colour of iron ions persists and } \\
\text { precipitate also persists, yet students } \\
\text { observed dissolution, which is not } \\
\text { possible. }\end{array}$ \\
\hline Deduce the salt given to you for analysis & $\mathrm{Fe}_{2} \mathrm{CO}_{3},, \mathrm{NaCl}, \mathrm{Al}, \mathrm{NaCO}_{3}, \mathrm{Na}_{2} \mathrm{CO}_{3}$ etc & $\mathrm{FeS}$ & \\
\hline
\end{tabular}




\section{Conclusion}

The study showed that pre-service teachers did not have adequate understanding of basic QA. These ACs had been retained from the senior high school through to University and most likely could be carried on to the students that they will teach in future thereby setting up a vicious cycle of misconceptions and poor performance in QA in school examinations Even at the tertiary level, students were unable to apply their additional knowledge in chemistry. The way QA is taught in schools need to be improved and supported by computer animations which will likely help students to remember pictorial reactions. The QADI proved to be a good instrument in diagnosing the pre-service teachers' common alternative concepts in inorganic chemistry qualitative analysis. The MCE was also a good intervention tool in addressing and solving most of the pre-service teachers' misconceptions. It is recommended that teachers use the QADI to diagnose similar problems and use other constructivist models such as concept mapping and analogies to solve their students' conceptual problems in chemistry.

\section{Implications}

If pre-service teacher hold inadequate cognition and ACs on the theory behind inorganic QA, then they would most likely pass these deficiencies on to their future students and by this set up a vicious cycle of ACs in the science, especially the chemistry discipline.

Interviews held with the pre-service teachers s suggested that students were not consistent with their own held ACs which suggested a lot of guesswork and poor deduction skills. In their presentations, correctly observed reactions led to incorrect inferences. It clearly indicated students' poor conceptions of the chemistry behind their observations.

Teachers will have to concentrate on conceptual basis in the drills they take their students through. Students must understand why particular reagents are used for the identification of specific test samples and the indicative reactions which ensue. This would lead to meaningful analysis which would male their students more critical thinkers and effective future laboratory analysts in industries. Pharmacists and other science based careers.

\section{References}

Ben- Zvi, R., Eylon, B. S. \& Silberstein, J. (1986) Is an atom of copper malleable? Journal of Chemical Educ., 63, (1) 64-66

Demircioglu, G., Ayas, A. \& Demircioglu, H. C. (2005). Conceptual change achieved through a new teaching programme on acids and bases. Chem Educ. Res. Pract, 6 36-51

Duit, R. \& Treagust, D. F. (1995) Students' conceptions and constructivist learning approaches. In Fraser, B. T. \& Walberg, H. J. (Eds). Improving science education (pp 46-69) Chicago, Illinois: The National Society for the Study of Education

Gunstone, R. F. (1994) The importance of specific science content in the enhancement of metacognition. In Fensham, P. J., Gunstone, R. F. \& White, R. T.(Eds). The 
content of science: A constructivist approach to its teaching and learning (pp 131 - 146) London: Falmer Press

Hart, C., Mulhall, P., Berry, A., Loughran, J. \& Gunstone, R. (2000). What is the purpose of this experiment? Or can students learn something from doing experiments? Journal of Research in Science Review. 73(264), 65-78.

Herron, J. D. 91996). The chemistry classroom: Formulas for successful teaching. Washington DC: American Chemical Society

Lenton, G. \& Turner, L. (1999). Student-teachers' grasp of science concepts. School Science Review, 81(295), 67-72.

Lin, H. S., Cheng, H. J. \& Lawrenz, F. (2000). The assessment of students' and teachers' understanding of gas laws. Journal of Chemical Education, 77(2), 235-237

Nakhleh, M. B. \& Krajcik, J. S. (1994). Influence of levels of information as presented by different technologies on students' understanding of acid, base and $\mathrm{pH}$ concepts. Journal of Research in Science Teaching 31 (10) 1077-1096

Odom, A. L. \& Barrow, L. H. (1995) Development and application of a two tier diagnostic test measuring college biology students' understanding of diffusion and osmosis after a course of instruction. Journal of Research in Science Teaching 32 (1), 45-61

Palmer, D. H. (1999) Exploring the link between students' scientific and nonscientific conceptions: Science Education, 83(6), 639-653

Quilez-Pardo, J. \& Solaz-Portoles, J. J. (1995). Students' and teachers' misapplication of Le Chateliers' principle: Implications for the teaching of chemical equilibrium. Journal of Research in Science Teaching, 32(9), 939-957.

Taber, K. S. (1999) Alternative frameworks in chemistry .Education in Chemistry, $36(5), 135-137$

Tan, K. C. D. (2000) Development and application of a diagnostic instrument to evaluate secondary students' conceptions of qualitative analysis. Curtin University of Technology, Western Australia.

Tan, K. C. D., Goh, N. K., Chia, L. S. \& Treagust, D. F. (2001) Secondary students' perceptions about learning qualitative analysis in inorganic chemistry. Research in science \& Technology Education, 19(2), 223-234

Tan, K. C. D., Goh, N. K., Chia, L. S. \& Treagust, D. F. (2002). Development and application of a two-tier multiple choice diagnostic instrument to assess high school students' understanding of inorganic chemistry qualitative analysis. Journal of Research in Science Teaching, 39(4), 283-301

Tan, K. C. D. \& Treagust, D. F (1999) Evaluating students' understanding of chemical bonding. School Science Review, 81(294), 75-83

Treagust, D. F. (1995) Diagnostic assessment of students' science knowledge. In S. M. Glynn \& R. Duit (Eds) Learning science in the schools: Research reforming practice (pp 327-346). Mahwah, New Jersey, Lawrence Erlbaum Associates 
Tyson, L., Treagust, D. F. \& Bucat, R. B. (1999) The complexity of teaching and learning chemical equilibrium. Journal of Chemical Education. 76 (4), 554558

Valanides, N. (2000). Primary student teachers' understanding of the particulate nature of matter and its transformation during dissolving. Chemistry Education Research and Practice in Europe, 1(2), 249-262

West African Examinations Council (2004). Chief Examiners' Report for Senior Secondary School Certificate Examination. Accra: West African Examination Council.

West African Examinations Council (2006). Chief Examiners' Report for West African Senior Secondary School Certificate Examination. Accra: West African Examination Council.

Wittrock, M. C. (1994) Generative science teaching. In Fensham, P. J., Gunstone, R. F., \& White, R. T. (Eds). The content of science: A constructivist approach to its teaching and learning (pp 225-262) London. Falmer Press. 


\section{Appendix A Examples of Qualitative analysis exercises}

\begin{tabular}{|c|c|c|}
\hline Test & Observation & Inference \\
\hline $\begin{array}{l}\text { a. F+ water and shaken } \\
\text { b. F + Dil. } \mathrm{HCl} \text { and warmed }\end{array}$ & $\begin{array}{l}\text { No observable reaction or F does } \\
\text { not dissolve } \\
\text { Effervesence occurs; Colourless, } \\
\text { odourless gas evolved } \\
\text { Gas turns lime water milky }\end{array}$ & $\begin{array}{l}\text { Insoluble salt } \\
\text { Gas is } \mathrm{CO}_{2} \\
\mathrm{CO}_{3}{ }^{2-} \text { present }\end{array}$ \\
\hline $\begin{array}{l}\text { Filtrate }+\mathrm{NaOH} \\
\text { dropwise and then in } \\
\text { excess } \\
\text { Filtrate }+\mathrm{NH}_{3}(\mathrm{ao}) \text { in } \\
\text { drops and then in excess }\end{array}$ & $\begin{array}{l}\text { Dirty green gel precipitate (ppt) } \\
\text { Dirty green gel ppt insoluble in } \\
\text { excess reagent }\end{array}$ & $\begin{array}{l}\mathrm{Fe}^{2+} \text { present } \\
\mathrm{Fe}^{2+} \text { present } \\
\text { - } \quad \text { Student must say that ppt is } \\
\text { insoluble to score the } \\
\text { inference }\end{array}$ \\
\hline
\end{tabular}

In step 1, what happened when water was added to the given salt?
a. Salt dissolved to for a precipitate
b. b. a precipitate was formed
c. c. Salt dissolved
d. d. F did not dissolve

Reason

In step $2 \mathrm{CO}_{3}{ }^{2-}$ is obtained because

Reason 